Res Publica. Revista de Historia de las Ideas Políticas

ISSN-e: 1989-6115

\title{
Desplegando a Melusina. Acerca de un proyecto inconcluso de Walter Benjamin*
}

\author{
Teresa Vinardell Puig**
}

Recibido: 14 de febrero de 2019 / Aceptado: 4 de octubre de 2019

Resumen. Durante largo tiempo Walter Benjamin acarició la idea de escribir un ensayo sobre el cuento "La nueva Melusina", de Johann Wolfgang von Goethe, aunque nunca llegó a realizar su propósito. Se ha señalado ya, acertadamente, la afinidad de este relato con la micrología benjaminiana. El presente artículo desarrolla cómo el cuento de Goethe, refleja en su argumento aspectos extrapolables a cómo concibió Benjamin el arte del narrador y la tarea del filólogo. Asimismo se encuentran analogías entre el texto de Goethe y algunas de las ideas de Benjamin sobre la naturaleza de la infancia y la evocación o el sentimiento amorosos.

Palabras clave: Walter Benjamin; interpolación; narración; infancia; amor.

\section{[en] Unfolding Melusine: About an Unfinished Project by Walter Benjamin}

Abstract. For a long time Walter Benjamin thought about writing an essay on Johann Wolfgang von Goethe's tale "Die neue Melusine", although he never actually carried out this project. The affinity of this story with Benjamin's micrology has already been rightly indicated. This article develops how Goethe's tale reflects in its plot some aspects of Benjamin's conception of the storyteller's art and the task of philologists. There are also some analogies between Goethe's text and several thoughts by Benjamin on the nature of childhood, love feelings and loving evocation.

Keywords: Walter Benjamin; Interpolation; Storytelling; Childhood; Love.

Sumario: [Introducción] - El abanico de la interpolación - Inocencia subversiva de la infancia - Plegarse y desplegarse. Dinámica de la narración - La erótica del pliegue - Narración sin curación - [Conclusiones]

Cómo citar: Vinardell Puig, T. (2019). Desplegando a Melusina. Acerca de un proyecto inconcluso de Walter Benjamin, en Res Publica 22.3, 659-671.

Durante largo tiempo Walter Benjamin acarició la idea de escribir un ensayo sobre el cuento "La nueva Melusina", de Johann Wolfgang von Goethe, aunque nunca llegó a realizar su propósito. Algunos estudios han señalado ya la afinidad de este cuento,

\footnotetext{
* El presente artículo fue elaborado en el marco del Proyecto de I+D del Programa Estatal de Fomento de la Investigación Científica y Técnica de Excelencia "El género, la mujer y lo femenino en las referencias de los siglos XVIII y XIX estudiadas por Walter Benjamin” (FFI 2015-70273-P).

** Facultad de Humanidades, Universitat Pompeu Fabra teresa.vinardell@upf.edu
} 
por el que el filósofo expresó su admiración en varias ocasiones, con la micrología benjaminiana $^{1}$. Las siguientes líneas son un intento de enlazar ese proyecto inconcluso de Benjamin con algunas de las reflexiones generales de este sobre la naturaleza de la infancia, la narración y el amor. Para ello me centraré en los puntos de contacto entre el argumento del relato, la dinámica de la narración como alternancia entre el plegarse y el desplegarse, tal como queda sugerida en el ensayo de Benjamin El narrador (1936/37), y en algunas reflexiones sobre las características de la infancia, la evocación y el sentimiento amorosos que el pensador alemán formuló en distintos textos.

\section{El abanico de la interpolación}

En una carta fechada el 14 de febrero de 1921 Walter Benjamin comunica a Gerschom Scholem lo mucho que le ha conmovido la lectura de "La nueva Melusina", un texto que le ha dado pie a pensar cómo podría ser la tarea de interpolar, de la cual no da demasiados detalles en la misiva, aunque sí identifique el género de la crónica como "historia interpolada" ["interpolierte Geschichte"] ${ }^{2}$. Hacia 1918, Benjamin ya había reflexionado en un apunte sobre distintos métodos de abordar la historia, distinguiendo tres de ellos, que atienden bien al transcurso del tiempo, bien a los fenómenos en sí mismos o bien a la terminología propia de cada época ${ }^{3}$. Llama la atención la conexión que Benjamin establece en la misiva entre el relato de Goethe, el género de la crónica y la tarea de interpolar. Peter Fenves subraya el vínculo entre interpolación y discontinuidad al definir la primera, en la disciplina filológica, como el proceso de agregar palabras, frases o pasajes enteros en un texto para reconstruir el sentido de éste. Para el joven Benjamin -afirma Fenves- la interpretación auténticamente filológica consistiría en reconocer y revertir en un texto una interpolación tras otra, reduciéndolo hasta su mínima y más genuina expresión ${ }^{4}$. Como veremos,

Cf., por ejemplo, S. Sontag, "Bajo el signo de Saturno”, en S. Sontag, Bajo el signo de Saturno, traducción de J. Utrilla Trejo revisada por A. Mayor, Barcelona, Random House Mondadori, 2007, pp.117-143, aquí p. 134, y S. Arribas, "El mundo en miniatura de Goethe y Walter Benjamin: Promesa de felicidad y ruina en La nueva Melusina", Constelaciones. Revista de Teoría Crítica, 2, 2010, pp. 61-78.

2 "Defino la filología no como ciencia o historia del lenguaje, sino — en su estrato más profundo- como historia de la terminología, aun cuando con toda seguridad uno se enfrente entonces con una noción del tiempo y unos fenómenos extraordinariamente enigmáticos. También intuyo, aunque no pueda desarrollarlo, lo que usted sugiere, que es, si no me equivoco, que la filología se encuentra cerca de la historia, considerada desde la crónica. En principio la crónica es historia interpolada. En las crónicas la interpretación filológica saca a relucir sencillamente la intención del contenido en la forma, pues el contenido es historia interpolada. A raíz de la lectura de una obra que me ha conmovido profundamente y que me ha estimulado a interpolarla, he experimentado con toda viveza cómo podría ser esta forma de trabajar. Se trata de «La nueva Melusina», de Goethe. ¿La conoce? Si no, le recomiendo en cualquier caso que [...] la lea sin más, esto es sin el marco en el que se halla inserta, como me ocurrió a mí por pura casualidad". W. Benjamin, Gesammelte Briefe, edición de C. Gödde y H. Lonitz, Fráncfort del Meno, Suhrkamp, 1995-2000, vol. II, p. 137. Cuando no se indica lo contrario, la traducción es mía.

3 W. Benjamin, Gesammelte Schriften, edición de R. Tiedemann y H. Schweppenhäuser, con la colaboración de G. Scholem y T. W. Adorno, Fráncfort del Meno, Suhrkamp, 1972, vol. VI, pp. 93-94.

$4 \quad$ P. Fenves, The Messianic Reduction. Walter Benjamin and the Shape of Time. Stanford (Cal.), Stanford University Press, 2011, p. 237. El investigador americano señala que las referencias a la filología en el intercambio epistolar entre Benjamin y Scholem están relacionadas con la nueva orientación intelectual de este último, quien pasó de estudiar matemáticas a interesarse por la Cábala. 
la imagen menguante de este proceso depurativo quedará reflejada en los cambios físicos que experimentan los protagonistas del relato de Goethe.

Algunos años más adelante, en un pasaje de Calle de dirección única (1928) en el que reflexiona sobre la evocación amorosa, el autor retomará el concepto de la interpolación, ilustrándolo mediante la imagen de un abanico que va desplegándose lentamente:

Todo el mundo habrá tenido la experiencia siguiente: cuando se ama a una persona, incluso cuando sólo se piensa intensamente en ella, casi no hay libro en el que no se descubra su retrato. Y hasta se presenta como protagonista o antagonista. En los relatos, novelas y cuentos reaparece en metamorfosis siempre nuevas. Y de esto se deduce: la capacidad de la fantasía es el don de interpolar dentro de lo infinitamente pequeño, de inventarle una plenitud nueva, compacta, a cada intensidad que se traduzca en extensión; en pocas palabras, de considerar cada imagen como si fuera la de un abanico cerrado que sólo toma aliento al desplegarse, y en su nueva dimensión, exhibe los rasgos de la persona amada que ocultaba en su interior ${ }^{5}$.

Cada varilla vendría a ser una imagen suscitada por una lectura cualquiera. Entre ésta y la siguiente, el enamorado intercalaría los rasgos de la persona amada. Hacia el final de su vida, en la colección de fragmentos "Zentralpark" (1938-1939), Benjamin opondrá el carácter progresivo de ese acto de recordar ["Erinnerung"], que apela a la experiencia ["Erfahrung"], al corto recorrido de lo que él denomina una "reliquia secularizada": el recuerdo-souvenir ["Andenken"], en el que cristaliza "la creciente alienación del hombre, que hace el inventario de su pasado como si de un bien muerto se tratase" 6 . Precisamente la alienación del ser humano, propiciada por la economía capitalista ligada a un desarrollo tecnológico voraz, será uno de los temas tratados por el filósofo alemán al repensar la función del narrador.

El 11 de junio de 1925 Walter Benjamin se dirige al poeta Hugo von Hofmannsthal para anunciarle su intención de escribir sobre "La nueva Melusina". El interés de Benjamin por ese relato se ha desplazado hacia la especificidad de la forma Märchen o cuento de hadas, que en este caso no es de tradición oral popular, sino que fue cuidadosamente construido por Goethe ${ }^{7}$. El título hace referencia a una leyenda, fijada por Jean d'Arras entre 1387 y 1392 en el Livre de Mélusine ou La noble histoire de Lusignan, en la que se funden tres núcleos distintos que aparecen por separado en numerosos cuentos folklóricos: el encuentro de un ser sobrenatural y un humano, los beneficios que éste obtiene mientras respeta las condiciones que le impone aquél y el castigo que sufre al transgredirlas y, por último, el regreso del ser sobrenatural a su mundo, en forma de dragón o serpiente ${ }^{8}$. Las hadas melusinianas se incorporan al mundo terrenal

5 W. Benjamin, Dirección única, traducción de J. J. del Solar y M. Allendesalazar, Madrid, Alfaguara, 2002, pp. 57-58 (cf. W. Benjamin, Gesammelte Schriften, op. cit., vol IV.1, p. 117).

6 W. Benjamin, Gesammelte Schriften, op. cit., vol. I.2, p. 681. Cf. al respecto M. E. Vázquez 1996, p. 26.

7 "Este trabajo, que planeo desde hace años, no deberá contraponer el tema literario al trasfondo de la figura de Goethe, como en el estudio de las Afinidades electivas, sino proporcionar visibilidad a este cuento de autor [«Kunstmärchen»] relacionándolo con el cuento de hadas popular [«Volksmärchen»]. Tendré que investigar especialmente la forma del cuento, puesto que tengo en mente una definición de éste que de los detalles de su forma deduce aspectos muy esenciales". W. Benjamin, Gesammelte Briefe, op. cit., vol. III, p. 51.

8 C. Alvar, "Prólogo", en J. d'Arras, Melusina o la noble historia de Lusignan, Madrid, Siruela, 1983, segunda edición corregida, pp. IX-XVI, aquí p. XII. 
con el fin de iniciar o ampliar su propio linaje con la ayuda de un varón humano. En la base de esta relación desigual, se halla un pacto impuesto por el ser feérico que en algún momento es violado por el hombre, causando la huída del hada ${ }^{9}$ En el ámbito germano-hablante la historia de Melusina es retomada por Thüring von Ringoltingen a mediados del siglo $\mathrm{XV}^{10}$. Goethe parte de esta última versión para reformular el argumento en "La nueva Melusina", sustituyendo el último núcleo por la huída in extremis por parte del narrador y coprotagonista del mundo diminuto al que pertenece su amada, la cual en este caso, además, no es un hada, sino descendiente de los enanos.

\section{Inocencia subversiva de la infancia}

Como decía, el mencionado proyecto de Benjamin no llegó a materializarse jamás, pero el deseo de llevarlo a cabo duró hasta el final de los días del pensador alemán. Varias son las razones que explican ese interés tan prolongado. Aparte de la sutileza con la que Goethe, según Benjamin, refleja argumentalmente los procesos de ampliar un texto interpolándolo para intentar comprenderlo mejor y de restituirle con posterioridad su laconismo original, otro motivo sería la relación del cuento con la infancia, etapa de la vida a la que Benjamin se sentía estrechamente ligado gracias a su fascinación por los libros ilustrados, los juguetes o la creatividad de los niños. $\mathrm{Su}$ interés está muy lejos de una visión ñoña o sentimental de éstos. El autor reconoce el potencial subversivo de esta etapa vital. "Superar las formas burguesas de la infancia y la educación" significa para él la posibilidad de "conservar y perpetuar la promesa de felicidad implícita en la infancia y de realizarla facilitando el camino a una nueva pedagogía"11. La afinidad de los cuentos de hadas con algunas estrategias infantiles para incorporarse al mundo y, a la vez, aprehenderlo y transformarlo, está relacionada con la abundancia de metamorfosis que se dan en ellos. La niñez se caracteriza por un deseo irrefrenable de disfrazarse o mimetizarse con la realidad circundante. Ese deseo se traslada también al lenguaje. El niño vincula fenómenos o palabras entre sí al constatar algún tipo de analogía entre ellos, con la esperanza de que ese parecido, por remoto que sea, constituya un camino que le conduzca al interior de lo que le rodea, que ansía conocer y comprender ${ }^{12}$. La magia, tan presente en los cuentos, alude al hecho de que esas analogías no tienen por qué ser evidentes para ser efectivas, y también a la certeza de que el mundo es habitable, pese a todas sus dificultades y asperezas. Como veremos, en el cuento de Goethe, la protagonista a la que alude el título hace gala de una facultad verdaderamente asombrosa de alterar su tamaño. Hasta que el narrador no se sienta amenazado por esta capacidad, permanecerá al lado de ella.

\footnotetext{
9 L. Harf-Lancner, Morgana e Melusina. La nascita delle fate nel Medioevo, traducción del original francés de S. Vacca, Turín, Einaudi, 1989, pp. 125-126.

10 J. W. Goethe, Los años itinerantes de Wilhelm Meister, edición de M. Salmerón Infante, Madrid, Cátedra 2017, p. 498 , nota 458 .

11 J. Zipes, "Walter Benjamin, Children's Literature, and the Children's Public Sphere: An Introduction to New Trends in West and East Germany", The Germanic Review, enero 1988, pp. 2-5, aquí p. 3, DOI: 10.1080/00168890.1988.9935431, versión online https://www.researchgate.net/publication/232948388_Walter_Benjamin_Children's_Literature_and_the_Children's_Public_Sphere_An_Introduction_to_New_Trends_in_West_and_East_Germany (18/12/2018).

12 A. Montané, “Tot el món deformat de la infantesa”, Comprendre, 18/1, 2016, pp. 95-104, aquí pp. $100-101$.
} 
En el relato "Conversación sobre el Corso. Ecos de un carnaval en Niza", publicado bajo pseudónimo en 1935, Benjamin vuelve a referirse explícitamente a "La nueva Melusina" por boca del narrador, quien considera que la protagonista del cuento es "la más perfecta encarnación de la inocencia" propia de la niñez"13. El danés, uno de los interlocutores de quien narra, puntualizará que, en su opinión, "la inocencia infantil no sería humana, si no se encontrase a sus anchas" tanto en el "mundo de lo frágil y lo diminuto" ["Welt der Zarten und Winzigen"], que ha cautivado al narrador al leer "La nueva Melusina", como en el mundo de "lo ógrico" o descomunal ["das Menschenfresserische"] ${ }^{14}$, y que es precisamente la capacidad de pasar del uno al otro "sin la menor complicación" y sin necesidad de "compromiso con el mundo opuesto" lo que caracteriza a los niños ${ }^{15}$. En cambio, los adultos tendemos siempre a hacer componendas: "Es cierto que podemos inclinarnos hacia lo diminuto, pero somos incapaces de integrarnos por completo en él, y probablemente nos divierta lo desorbitado [«das Ungeheure»], pero no sin un leve encogimiento [«Befangenheit»]" ${ }^{\text {. }}$. Benjamin concluye la conversación con un alegato del danés a favor de la intensidad y radicalidad infantiles, de las que los mayores podrían aprender a comportarse con mayor desenvoltura y generosidad. La lectura benjaminiana de "La nueva Melusina" queda teñida, pues, por la añoranza de un mundo a la vez decidido y confiado, en el que uno no tuviese que pensar siquiera en ser precavido y se lanzara sin más a gozar de la existencia. Una existencia no amputada por la estrechez convencional de la vida adulta, que niega muchas posibilidades a las vidas de la siguiente generación ${ }^{17}$.

\section{Plegarse y desplegarse. Dinámica de la narración}

En "El narrador" Benjamin opone el concepto de "narración", que define como un arte ["Kunst des Erzählens"], al de "información" ["Information"] 18. La diferencia más notable entre ambos es que la primera hunde sus raíces en "la facultad concreta de intercambiar experiencias [«das Vermögen, Erfahrungen auszutauschen»]"19, mientras que la segunda surge en el seno del aislamiento inconmensurable del hombre contemporáneo. De la información, Benjamin destaca su carácter "perfectamente comprensible" ["an und für sich verständlich"], su imperiosa necesidad de verosimilitud, y por ende también su cautela ante "lo extraordinario" ["das Außerordentliche"], que es en cambio aquello en lo que se recrea la narración ${ }^{20}$. Para

\footnotetext{
13 W. Benjamin, Historias y relatos, traducción de G. Hernández Ortega, Barcelona, Península, 1997, p. 92. (cf. W. Benjamin, Gesammelte Schriften, op. cit., vol. IV.2, p. 769).

14 Ibidem, p. 94. (cf. W. Benjamin, Gesammelte Schriften, op. cit., vol.IV.2, p. 770).

15 Ibidem, pp. 94-95. (cf. W Benjamin, Gesammelte Schriften, op. cit., vol. IV.2, p. 770).

16 Ibidem, p. 95. (cf. W. Benjamin, Gesammelte Schriften, op. cit., vol. IV.2, p. 771).

17 Cf. al respecto A. Lanfranconi, Walter Benjamin: Infancia y politización, tesis doctoral Universidad de Barcelona, 2017, versión online: https://www.tdx.cat/handle/10803/461379 (17/12/2018).

18 W. Benjamin, Obras, edición de R. Tiedemann y H. Schweppenhäuser, con la colaboración de T. W. Adorno y G. Scholem, edición española al cuidado de J. Barja, F. Duque y F. Guerrero, Madrid, Abada, 2006-, vol II.2, pp. 41 y 47, respectivamente (cf. W. Benjamin, Gesammelte Schriften, op. cit., vol. II.2, pp. 432 y 444, respectivamente).

19 Ibidem, p. 41 (cf. W. Benjamin, Gesammelte Schriften, op. cit., vol. II.2, p. 439).

20 Ambas citas ibidem, p. 47 (cf. W. Benjamin, Gesammelte Schriften, op. cit., vol. II.2, p. 444).
} 
ésta, que pretende transmitir lo vivido, la concisión es mérito y estrategia. Benjamin afirma que el escritor ruso Nikolái Léskov contaba lo extraordinario en sus relatos con la máxima precisión, pero sin imponer jamás al lector el contexto psicológico de lo acaecido. Y es que, según Benjamin, las historias que púdicamente ["keusche Gedrungenheit' $]^{21}$ dejan en suspenso el análisis psicológico, encuentran con mayor facilidad un modo de anclarse en la memoria y suelen contarse con mayor frecuencia. El proceso de asimilación de un relato y la posibilidad de ser rememorado están relacionados con la relajación mental profunda que antaño proporcionaban las tareas propias de formas de vida ancestral al fomentar la escucha atenta y el olvido de sí $^{22}$. Cabe destacar, por otra parte, que esa suerte de laconismo de la narración, al resistirse a aclaraciones y análisis, había de resultar muy afín a la propia práctica literaria y filosófica de Benjamin. Decía Theodor W. Adorno al respecto que la expresión en Benjamin tendía al aforismo y que "[1] e rondaba la idea de la comunicación de lo incomunicable a través de la expresión lapidaria"23.

En una interesante anotación sobre el personaje de Mickey Mouse de Walt Disney, fechada aproximadamente el 1931, Benjamin diagnostica que en las películas de dibujos animados "la humanidad se prepara para sobrevivir a la civilización"24, porque ahí se pone de manifiesto que "en semejante mundo no merece la pena tener experiencias", ni menos aún acumularlas ${ }^{25}$. Sin embargo, las películas del ratón Mickey, según observa Benjamin, no renuncian a acogerse formalmente a algunos patrones arcaicos que muestran un gran parecido con los de los cuentos de hadas: "Todas las películas de Mickey Mouse tienen como motivo la partida para aprender a tener miedo" - dice Benjamin en clara alusión a Juan sin miedo, un conocido cuento recopilado por los hermanos Grimm, que en alemán se titula "De uno que partió para aprender lo que era temer" 26 . La anotación tiene su enjundia porque aventura la idea de que en creaciones de rabiosa actualidad, como lo eran en la década de 1930 los dibujos animados ${ }^{27}$, perviven estructuras antiquísimas, a pesar de que el propósito que éstas hubiesen tenido en origen -formalizar la experiencia con el fin de transmitirla- perdiera su vigencia con posterioridad.

Al Benjamin de los años 20 y 30 le interesan las formas épicas simples, breves. Ese interés no es privativo del filósofo, sino compartido por otros estudiosos de su tiempo como, por ejemplo, André Jolles, quien publica el libro Einfache Formen (Formas simples) en 1930 y es considerado todavía hoy un precursor de los planteamientos morfológicos del folklore. A diferencia de Jolles, Benjamin no contrapone el origen y los efectos del cuento popular (Volksmärchen) y el cuento de autor (Kunstmärchen), una distinción de larga tradición, recogida en una polémica de 1813 entre Achim von Arnim y Wilhelm Grimm, a la que sí se refirió Jolles ${ }^{28}$. La trayectoria

\footnotetext{
W. Benjamin, Gesammelte Schriften, op. cit., vol. II.2, p. 446.

W. Benjamin, Obras, op. cit., vol. II.2, pp. 49-50.

23 Th. W. Adorno, "Introducción a los escritos de Benjamin" en: Th. W. Adorno, Sobre Walter Benjamin. Recensiones, artículos, cartas, texto fijado y anotado por R. Tiedemann, traducción de C. Fortea, Madrid, Cátedra, 1995 , pp. 35-53, aquí p. 47.

24 W. Benjamin, Mickey Mouse, selección y traducción de W. Erger, Madrid, Casimiro, 2018, p. 7 (cf. W. Benjamin, Gesammelte Schriften, op. cit., vol. VI, p.144).

25 Ibidem, p. 8.

26 Ibidem, (cf. W. Benjamin, Gesammelte Schriften, op. cit., vol. VI, p.145).

27 Los cortos animados de Mickey Mouse se presentaron por primera vez al público en 1928. C. Suddath, "Mickey Mouse", Time 18/11/2008, http://content.time.com/time/printout/0,8816,1859935,00.html (20/05/2018).

28 A. Jolles, Einfache Formen. Legende, Sage, Mythe, Rätsel, Spruch, Kasus, Memorabile, Märchen, Witz, Tubin-
} 
política de éste, que se afilió al partido nazi en los albores del Tercer Reich y que, al parecer, se mantuvo fiel a sus consignas hasta el final (se suicidó en 1946) ${ }^{29}$, muestra hasta qué punto las reflexiones sobre la literatura popular, por muy novedosas que fuesen desde el punto de vista metodológico, podían enlazar sus planteamientos con la ideología "völkisch", esto es ultraconservadora y fuertemente teñida de nacionalismo, que cimentaba su autoridad en la supuesta pureza étnica de sus orígenes. Probablemente, la marcada tendencia del nacionalismo conservador a apropiarse de lo popular para sus propios fines fue uno de los motivos de que Benjamin previese la dimensión política de su proyecto sobre "La nueva Melusina" 30 .

El interés de Benjamin por los cuentos es de naturaleza distinta del de Jolles: Benjamin se siente atraído por las formas breves como el cuento porque ve en ellas la capacidad de crear recursos perdurables para una comunicación auténtica y profunda, capaces de adaptarse incluso a cambios sociales y culturales de largo alcance, recursos a los que en algún momento incluso parece atribuir propiedades sanadoras, como veremos, y que podrían extrapolarse a otros lenguajes, como el cinematográfico $^{31}$. El pensador reflexiona sobre las características e implicaciones de una cierta forma de narrar que detecta tanto en relatos de origen anónimo como en otros de autoría conocida, como es el caso de "La nueva Melusina" o los cuentos de Nikolái Léskov. En "El narrador", Benjamin explica la dinámica inherente al acto de contar como una fuerza que extrae su potencia de dos extremos polarizados. Por un lado encontramos el relato compacto, que se resiste a cualquier tipo de aclaración o interpolación y que, en consecuencia, no se entrega con facilidad a quien lo escucha, y por el otro hallamos al oyente receptivo, que placenteramente se abandona a los encantos de una historia bien contada. Esa tensión persistente entre ambos extremos no existe en el proceso de descodificar información, y es lógico que así sea, puesto que este proceso tiene a gala su propia eficiencia, esto es la rapidez, claridad y fiabilidad con la que se lleva a cabo:

La información tiene interés tan sólo en el breve instante en el que es nueva. Sólo está viva durante ese instante, y a él se entrega por completo sin tener ningún tiempo que perder. Pero la narración jamás se entrega, sino que, al contrario, concentra sus fuerzas, $y$, aún mucho después, sigue siendo capaz de desplegarse ${ }^{32}$.

Así como en el amor la distancia alimenta el deseo, la tensión entre el acto de abandonarse al relato y el de desentrañarlo aumenta la fascinación que éste ejerce, convirtiendo al oyente o al lector en un sujeto activo y potencialmente transforma-

ga, Niemeyer, 1982, pp. 222-225. La historia de la recepción de los cuentos de Grimm muestra hasta qué punto el proyecto de éstos fue instrumentalizado por los nazis. Véase M. Tatar, "Grimms Märchen”, en: E. François y H. Schulze (eds.), Deutsche Erinnerungsorte, Munich, C.H. Beck, 2009, vol. I, pp. 275-289, aquí p. 281.

29 B. Emmrich, "Jolles, André (eigentl. Johannes Andreas, Pseudonym: Karl Andres)", Sächsische Biografie, edición del Institut für Sächsische Geschichte und Volkskunde, edición online: http://saebi.isgv.de/biografie/ Andr\%C3\%A9_Jolles_(1874-1946) (17/10/2018).

30 El 19 de febrero de 1925, Benjamin escribe a Scholem que en su trabajo sobre el cuento de Goethe quiere "regresar a lo romántico y (tal vez ya) avanzar en lo político". Cf. W. Benjamin, Gesammelte Briefe, op. cit., vol. III, p. 15.

31 En sus apuntes sobre la narración, Benjamin anota: "No llorar. Sobre el sinsentido de los pronósticos críticos. Cine en lugar de narración.” W. Benjamin, Gesammelte Schriften, op. cit., vol. II.3, p. 1282.

32 W. Benjamin, Obras., op. cit., vol. II.2, p. 48; cf. W. Benjamin, Gesammelte Schriften, op. cit., vol. II.2, pp. 445-446. 
dor. Como veremos, el cuento de "La nueva Melusina" muestra ese desplegarse y replegarse, ejemplificándolo en la figura principal femenina, que aparece y desaparece y que en ocasiones crece o se encoge. Los vaivenes de toda narración, que con un cierto grado de hermetismo a la vez se ofrece y se niega al oyente o al lector, se reflejan también en la actitud oscilante que caracteriza a este personaje femenino y en las fluctuaciones del deseo que ello despierta en el narrador y coprotagonista. La historia es referida en Los años itinerantes de Wilhelm Meister (1829) por un barbero inicialmente taciturno ${ }^{33}$. Aun cuando Benjamin recomendase a Scholem prescindir del marco en el que se insertaba el cuento ${ }^{34}$, no deja de resultar significativo que, en la novela, el barbero sea presentado como alguien que casi ha renunciado a hablar, pero al que se le reconoce el don de saber contar ${ }^{35}$. El barbero refiere sus amores con una bella mujer, de quién nunca revela el nombre, a la que dice haber conocido por azar durante un viaje. A pesar de una actitud inicialmente distante por parte de ella, reacia a tratar cualquier tema relacionado con "sentimientos del alma" y con el amor en particular ${ }^{36}$, ambos acaban intimando, siendo el barbero quien se enamora primero de la hermosa joven. Ella afirma tener que ausentarse y le pide a su amigo que le custodie un cofrecillo muy preciado. Antes de partir incluso se ofrece a sufragar cualquier gasto ocasionado por el transporte del cofrecillo. El barbero, más bien juerguista y poco previsor, se arriesga en exceso y acaba medio arruinado y malherido. Como por arte de magia, en dos ocasiones reaparece la misteriosa joven salvándole la vida y proporcionándole recursos materiales en apariencia ilimitados, para que el barbero pueda seguir custodiando el cofre. Empieza un período de felicidad para ambos jóvenes, que se convierten en amantes. Ella queda embarazada, y este hecho contribuye a aumentar el gozo de la pareja, pero un día la mujer desaparece sin avisar ni dejar rastro. El barbero, perplejo y preocupado, percibe al proseguir solo su viaje un extraño resplandor que emerge del cofrecillo que su amada ha dejado atrás. Al escudriñar en su interior a través de una grieta, el barbero ve una habitación en la que se aloja una figura femenina diminuta, encinta, en la que reconoce a su compañera. Ésta regresa con su apariencia habitual, pero a partir del descubrimiento de ese extraño fenómeno, ya nada vuelve a ser igual para el narrador. No se siente tranquilo ni confía como antes en su amada, aunque tampoco se siente capaz de renunciar a ella. La joven le ruega que, si desea permanecer a su lado, no le reproche jamás su naturaleza metamórfica, cosa que el barbero le promete. Sin embargo, una noche, sintiéndose celoso, rompe su promesa encarándose con ella. Aunque posteriormente el barbero se arrepienta de sus exabruptos, se pone de manifiesto que una reconciliación entre ambos no es posible sin más. Condenada por la transgresión de su amado a abandonar la esfera de los humanos, la joven revela al barbero toda su historia: no sólo su rango de princesa en el linaje de los enanos, sino también lo que la ha llevado a recorrer mundo: la necesidad de su pueblo de combatir una endogamia que lo empequeñece cada vez más, hasta llevarlo hasta el borde de la extinción. Con el fin de renovar la sangre de los suyos, de vez en cuando alguien es enviado a buscar pareja

33 J. W. Goethe, Los años itinerantes de Wilhelm Meister, op. cit., p. 455 (cf. J. W. Goethe, Wilhelm Meisters Wanderjahre oder Die Entsagenden, en Werke, vol. IV, introducción de V. Lange y notas de A. Viviani, Munich, Winkler, 1984, pp.547-980, aquí p. 829).

34 Cf. nota 2.

35 J. W. Goethe, Los años itinerantes de Wilhelm Meister, op. cit., p. 498 (cf. J. W. Goethe, Wilhelm Meisters Wanderjahre, op. cit., p. 863).

36 Ibidem, p. 501 (cf. J. W. Goethe, Wilhelm Meisters Wanderjahre, op. cit., p. 864). 
entre los humanos. Para pasar desapercibida y confundirse con las otras mujeres, la princesa utiliza los poderes de un anillo mágico, que le permiten cambiar de tamaño a voluntad. El haber sido despreciada por el barbero por ser como es, sin embargo, la obliga a volver a su patria. Su amante, compungido, se ofrece a acompañarla en su camino de regreso hasta donde sea posible, pero en el momento de la despedida el deseo de permanecer junto a ella le embarga. La única solución para no tener que separarse -según explica la princesa- es que el joven consienta en encogerse y que la siga hasta su lugar de origen. La propuesta inquieta al barbero, aunque acabe aceptándola. El anillo disminuye su estatura y ante sus ojos el cofrecillo se despliega hasta convertirse en un fastuoso palacio. Recibe a la pareja el rey de los enanos, el cual los emplaza a casarse al día siguiente. La boda se celebra, aunque previamente el barbero, presa del desasosiego, ha intentado huir sin éxito. Después del enlace y a pesar de la dulzura de su flamante esposa, el recién casado no puede olvidar su vida y aspecto anteriores, que guardan correspondencia con el ideal que sigue teniendo de sí mismo. Por ello decide quitarse el anillo para así volver a ser como antes. Tras conseguirlo, se siente abatido, sumido en la soledad y la sensación de pérdida ${ }^{37}$. Junto a él encuentra el cofrecillo: una llavecita le permite abrirlo y tomar el dinero que todavía contiene. Lo irá gastando, y cuando se le acabe, venderá su carruaje. De lo último de lo que se desprenderá será del pequeño cofre.

Este cuento se presenta como el relato de una experiencia compactada, que conserva sus luces y sombras, sin pretender aclararlas. Se encuentra, pues, entre los textos narrativos que no se limitan a transmitirnos mera información. Teniendo en cuenta las reflexiones de Benjamin acerca de la narración, a nivel argumental puede apreciarse reflejada la dinámica de plegarse y desplegarse propia de lo narrado y, como veremos, propia también de la ambivalencia amorosa.

\section{La erótica del pliegue}

Me refería antes a un pasaje de Calle de dirección única (1928) titulado "Abanico" (dentro del apartado "Antigüedades"), en el que Benjamin describe el íntimo vínculo de la fantasía con la evocación amorosa, que logra desplegar cualquier imagen e introducir en ella la de la persona amada. Como un delicado origami, el argumento de "La nueva Melusina" ilustra el recogimiento de quien añora, y las expansiones tanto del deseo como de la desconfianza. En su análisis de la lectura que Benjamin hace del cuento goetheano Sonia Arribas señala que las "metáforas espaciales del agrandamiento y el estrechamiento, o de la distancia y la proximidad" representan "la transformación en el tiempo de sus protagonistas. Se trata de un tiempo que en cualquier momento se interrumpe para traer consigo la plenitud o la catástrofe" 38 .

En otro pasaje de la misma obra ("ESTAS PLANTACIONES SE ENCOMIENDAN A LA PROTECCIÓN DEL PÚBLICO”), la vivencia del enamoramiento es descrita por el filósofo berlinés como una alternancia de momentos expansivos y de recogimiento:

J. W. Goethe, Wilhelm Meisters Wanderjahre, op. cit., p. 882. La versión traducida altera un poco el sentido de ese pasaje final del cuento (cf. J. W. Goethe, Los años itinerantes de Wilhelm Meister, op. cit., p. 520).

$38 \quad$ S. Arribas, op. cit., p. 68. 
[...] al contemplar a la mujer amada también estamos fuera de nosotros mismos. Aunque, en este caso, torturadamente tensos y embelesados. Deslumbrada, la sensación revolotea como una bandada de aves en el resplandor de la mujer. Y así como los pájaros buscan refugio en los frondosos escondites del árbol, las sensaciones huyen a las arrugas umbrosas, a los gestos sin gracia y a las manchas insignificantes del cuerpo amado, donde se acurrucan, seguras, como en un escondrijo. Y ningún paseante ocasional adivinará que precisamente ahí, en aquellos rasgos imperfectos, criticables, es en donde anida, veloz como una flecha, el ímpetu amoroso del adorador [“die pfeilgeschwinde Liebesregung des Verehrers"] ${ }^{39}$.

Benjamin, enamorado de la dramaturga letona Asja Lacis, a quien dedica el libro antes citado, caracteriza la naturaleza del vínculo amoroso, al menos desde la perspectiva masculina, como un pendular entre dos extremos. A un momento expansivo de deslumbramiento casi enajenador, le sigue la necesidad de replegarse para construir un lazo intenso con la persona amada que, entre otras cosas, permita poder experimentar nuevos instantes de redescubrimiento. Ese repliegue es descrito por Benjamin como un movimiento de la atención que momentáneamente se posa sobre las arrugas o lunares de la mujer amada. Éstos la definen con la misma intensidad que sus supuestas virtudes o atractivos físicos $\mathrm{y}$, sin embargo, la hacen accesible, atenuando su resplandor, alentando el sentimiento de proximidad y concediendo al amante una suerte de cobijo casi maternal. La amenaza -tal vez leve, pero constante - de la ambivalencia amorosa, queda recogida aquí en la metáfora de la flecha, empleada para caracterizar la emoción del enamorado. En otro pasaje de la misma obra, Benjamin recurre de nuevo a la imagen espacial del pliegue, tan característica de lo ambivalente, que aquí es visto como una forma de realce. La amada es recordada inclinándose hacia el amante. Su presencia proyecta así una sombra sobre las confidencias compartidas, "cuidando de que la idea, como un relieve, viviera en todos los pliegues y rincones", y evitando que ésta parezca plana y carente de enjundia ${ }^{40}$.

A pesar de que se ha interpretado el cuento de "La nueva Melusina" como una denuncia por parte de Goethe contra el amor interesado, propio de quien aspira al poder o pretende conservarlo, si ya lo detenta ${ }^{41}$, llama la atención que Benjamin se fije en aquellos otros aspectos del texto que tienen que ver con una suerte de dinámica interna de lo narrado y también con el precario y valioso equilibrio entre cercanía y distancia que caracteriza el eros. La estrechez del matrimonio burgués, diseccionada por Benjamin en el ensayo sobre Las afinidades electivas y satirizada en el cuento por Goethe ${ }^{42}$, haría imposible ese equilibrio. Una prueba de que Benjamin asociaba, sin embargo, "La nueva Melusina" a la escritura y al deseo, se encuentra en una carta, que el autor escribe a su amiga y antigua amante Jula Radt-Cohn el 9 de junio de 1926:

39 W. Benjamin, Dirección única, op. cit., pp. 24-25, (cf. W. Benjamin, Gesammelte Schriften, op. cit., vol. IV.1, p. 92).

40 Ibidem, p. 58, (cf. W. Benjamin, Gesammelte Schriften, op. cit., vol. IV.1, p. 117).

41 S. Gustafson, Goethe's Families of the Heart, Nueva York y Londres, Bloomsbury, 2017, pp. 179-184, C. Bürger, Goethes Eros, Fráncfort del Meno y Leipzig, Insel, 2009, pp. 207-218.

42 W. Benjamin, "Goethes Wahlverwandtschaften”, en W. Benjamin, Gesammelte Schriften, op. cit., vol. I.1, pp. 123-211, aquí pp. 127 y ss. 
Ya ves -vuelvo a estar en un período de letra pequeña en el que, tras largos intervalos de alejamiento, me encuentro otra vez como en mi casa, una casa a la que me gustaría invitarte empleando mi poder de persuasión ["Dich überredend einladen"]. Si encuentras acogedora esta cajita, entonces nada debería evitar que te convirtieras en su princesa. (Conoces a "La nueva Melusina”, ¿no?) ${ }^{43}$.

La cariñosa referencia a Melusina en la carta parece provenir de la ternura que evoca el pequeño tamaño de la cajita en la que se aloja el personaje. Sin embargo, podría ser que la atracción de Benjamin por el cuento se hubiera intensificado al empezar a interesarse Benjamin por el surrealismo a partir de $1925^{44}$. André Breton expresaría en 1964 que desde la adolescencia se sintió fascinado por las mujeres misteriosas, de sexualidad a la vez gélida y desbordada, por las enigmáticas hadas-amantes melusinianas como la "Fée au griffons" pintada por Gustave Moreau, imágenes de un concepto sublimado de lo femenino, con agudos contrastes de luz y sombra, que nutren con calculada ambigüedad la experiencia amorosa ${ }^{45}$. Pero esa fascinación ya se intuye mucho antes en el personaje de Nadja, protagonista de la novela homónima de Breton (1928). Se trata de seres cuyo atractivo estriba en mostrarse accesibles o distantes sin atenerse a ningún patrón de conducta previsible. De ahí que la mediación de los objetos que gustan o que rodean a estas mujeres, resulte imprescindible para aproximarse a ellas, y que las pertenencias de éstas puedan acabar suplantándolas. Ya en los apuntes para el artículo que publicaría en 1929 sobre ese movimiento artístico y literario, Benjamin, refiriéndose a Nadja (1928), afirma que

En el amor esotérico, la dama es lo menos importante. Siempre, así también Breton. Éste se halla más cerca de las cosas que son próximas a la amada, que a ésta misma. [...] Nadie puede tener una idea más precisa de cómo la miseria, no sólo la social sino también la arquitectónica, la miseria del interior, en suma, las cosas esclavizadas y esclavizadoras, se transforman repentinamente en nihilismo revolucionario radical ${ }^{46}$.

En relación al relato goetheano, esa reflexión sería aplicable al vivo interés del protagonista y narrador por la riqueza de su amada, especialmente por el cofrecillo. La mirada que escudriña el interior de éste acaba por cosificar a la joven y, para el barbero, que descubre el diminuto tamaño real de ésta, la relación se torna irreal, como un sueño. A partir de ese momento, el personaje se siente sumergido en la "sorpresa" y el "espanto" $"$.

\section{Narración sin curación}

Para finalizar quisiera volver a la acción de narrar y escuchar, un acto como aquél en el que se inserta "La nueva Melusina" en la novela de Goethe. Vicente Valero ha

\footnotetext{
43 W. Benjamin, Gesammelte Briefe, op. cit., vol. III, p. 171.

44 W. Benjamin, Gesammelte Schriften, op. cit., vol. II.3, p. 1018.

45 A. Breton, "Gustave Moreau", en A. Breton, Le surrealisme et la peinture, París, Gallimard, 1979 (nueva edición revisada y corregida), p. 363.

46 W. Benjamin, Gesammelte Schriften, op. cit., vol. II.3, p.1024.

47 J. W. Goethe, Los años itinerantes de Wilhelm Meister, op. cit., p. 507.
} 
reflejado en un hermoso ensayo la importancia del primer encuentro de Benjamin con las arcaicas formas de vida rural imperantes en la Ibiza de 1932 para la teoría de la narración del escritor berlinés. De lo escrito entonces por el pensador alemán, me gustaría rescatar "Narración y curación". Es una breve reflexión que el autor no llegó a incorporar en el ensayo "El narrador". Me parece que ese apunte aúna los dos aspectos -relativos a la exploración de los fenómenos amoroso y narrativo-implícitos en el proyecto ligado a "La nueva Melusina" que he querido presentar aquí. En este texto Benjamin se refiere a un arte de contar historias, alentado por el amor o la ternura, de efectos terapéuticos, si no salvíficos:

[...] N. me contó de la extraordinaria virtud curativa que habían tenido las manos de su mujer. De esas manos decía: "Sus movimientos eran muy expresivos. Pero no habría sido posible describir su expresión. Era como si estuvieran contando un cuento". [...] Sí, ¿no podría curarse incluso cualquier enfermedad si se la dejara fluir lo suficiente hasta la desembocadura sobre la corriente de la narración? Si se considera que el dolor es un dique que se opone a esta corriente, se ve claramente que este dique será desbordado cuando la corriente sea lo suficientemente fuerte como para conducir al mar del olvido feliz todo lo que encuentre su camino. Las caricias le dibujan un lecho a esa corriente ${ }^{48}$.

A principios de los años 30, Benjamin se había propuesto "participar activamente en la cadena de la tradición oral"49. Una de las personas que le instruirían y le reafirmarían en este propósito, fue Hans Jakob Noeggerath, hijo de un compañero de estudios en Munich, que le había proporcionado al filósofo un alojamiento en Ibiza. Hans Jakob era filólogo, un entusiasta recopilador de relatos populares ibicencos, y Benjamin le conoció durante su primera estancia en Ibiza. A causa de unas fiebres tifoideas contraídas allí, el joven folklorista murió en la isla en 1934, a la edad de 28 años. Por parte del filósofo, parece un signo de delicadeza respecto a la familia del difunto el hecho de descartar del ensayo sobre Léskov esas consideraciones acerca de un posible vínculo entre narración y curación. La ausencia de éstas me parece una renuncia, más que un rechazo, y presumo que fue hecha con pesar: en 1936, lamentablemente, Europa se había vuelto demasiado inhóspita como para enlazar entre sí y a efectos físicos extraordinarios el vínculo amoroso y la narración, dos fenómenos susceptibles de representarse de modo similar pero, lamentablemente, también frágiles. Por mucho que Benjamin hubiese experimentado felicidad y consuelo gracias a ambos, la hostilidad de su tiempo quizá le condujera a un punto en el que afirmar e intentar preservar la cada vez más infrecuente capacidad de transmitir experiencias ya le pareciese milagro suficiente: "el mar del olvido feliz", al que se refiere en el pasaje antes citado, había dejado de ser un espacio en el que flotar sin sentir el peso del sufrimiento, para adquirir tonalidades cada vez más siniestras.

El proyecto inconcluso sobre "La nueva Melusina" fue modulándose a lo largo del tiempo. Benjamin parece haber descubierto en ese relato un potente estímulo para reflexionar sobre algunas cuestiones que le interesaron profundamente a lo largo de

\footnotetext{
48 W. Benjamin, Denkbilder. Epifanías en viajes, selección y prólogo de Adriana Mancini, traducción de S. Mayer con la colaboración de A. Mancini, Buenos Aires, El cuenco de plata, 2011, p. 154 (cf. W. Benjamin, Gesammelte Schriften, op. cit., vol IV.1, p. 430).

49 V. Valero, Experiencia y pobreza. Walter Benjamin en Ibiza, Cáceres, Periférica, 2017, p. 45.
} 
su vida, como el potencial subversivo de la infancia, la dinámica de la narración y la ambivalencia amorosa. El cuento de Goethe no solo reflejó en su argumento aspectos extrapolables al seductor arte de narrar y a la más discreta tarea de interpolar, sino que dotó a las ideas de Benjamin sobre la evocación, la infancia y el amor de un sustrato narrativo a partir del cual poder articularse. 